\title{
A questão cidadania na sociedade da informação
}

\section{Marisa Perrone Campos Rocha}

Bibliotecária e assessora técnica na Câmara Legislativa do Distrito Federal. Possui curso de especialização em Análise de Sistemas, pela CTIS. Instrutora de Cursos da Associação dos Bibliotecários do DF (ABDF).

Mestranda em Ciência da Informação pela Universidade de Brasília.

e-mail: mperrone@solar.com.br

\section{Resumo}

No cerne das transformações que estão alterando o panorama mundial, a informação é recurso de poder, pela vinculação do desenvolvimento com a capacidade de uma sociedade em gerar e aplicar conhecimentos. A informação concorre, assim, para o exercício da cidadania, à medida que possibilita ao indivíduo compreender a dimensão dessa mudança e oferece os meios de ação individual e coletiva de auto-ajustamento. Para isso, no entanto, é necessário garantir ao indivíduo o acesso à educação e à informação.

\section{Palavras-chave}

Informação; Cidadania; Educação; Sociedade da Informação.

\section{Citizenship in the information society}

\begin{abstract}
In the midle of the alteration that are changing the world's general view, the information is appeal of power by entailment of development among society's capacity to criate and apply acquirements. Then the information concurs to the citizenchip's exercise, as the proportion to enable to the person to understand this change in its dimension and offer the way individual and general action of the adjustment. Meanwhile, this is necessary guarantee to the person the access to education and information.
\end{abstract}

\section{Keywords}

Information; Citizenship; Education; Information society.

\section{INTRODUÇÃO}

\author{
"O futuro emergirá como \\ resultado da ação humana"
}

(Peccei)

O homem cria sua própria realidade e, segundo Ferreira ${ }^{1}$, tem seus próprios recursos de compreender e interpretar essa realidade, torná-la lógica e significativa para o conjunto de indivíduos. Compreendendo, analisando e interpretando todas as dimensões da realidade, torna possível a interação e a organização social pela "existência de significados culturalmente compartilhados". Para garantir sua "movimentação contínua ante essa realidade permeada de descontinuidade", lança mão de mecanismos para superar barreiras e desafios. Quando esses esquemas tornam-se inoperantes, outros se interpõem. Esse processo está associado ao ciclo informacional e de assimilação do conhecimento.

É, pois, através do conhecimento do mundo, adquirido, formal e informalmente, a partir de suas experiências e do convívio em sociedade, pelas trocas lingüísticas e reconhecimento de símbolos, em um processo sistemático de formação intelectual e moral do indivíduo, que se processa a construção de sua dimensão enquanto cidadão.

Mas em que consiste ser cidadão? Como se constrói, como se manifesta, como se reconhece a cidadania? - indagamos -, fazendo eco às palavras de Targino ${ }^{2}$.

Nesse momento em que ondas de mudanças revolucionam as relações humanas, em todos os seus aspectos, fazendo emergir uma nova ordem social, que reflexões podemos fazer sobre o tema, buscando compreender os novos papéis sociais que se delineiam.

\section{A NOVA ORDEM MUNDIAL}

Ao observarmos o cenário internacional, identificamos os fatores indicativos das mudanças que alteram as relações sociais, econômicas e políticas, de âmbito mundial que tiveram início após a chamada Guerra Fria. Essas transformações apontam para uma nova ordem mundial, que, contudo, ainda não se encontra totalmente delineada. 
Nesse quadro de mudanças, Claus $\mathrm{Offe}^{3}$, ao referir-se às atribuições do Estado no cenário que se avizinha, apresenta-nos um novo pacto:

"Os problemas de um país não vão ser resolvidos apenas pela ação do Estado ou do mercado. É preciso um novo pacto, que ressalve o dever do Estado de dar condições básicas de cidadania, garanta a liberdade do mercado e da competição econômica e, para evitar o conflito entre esses dois interesses, permita a influência de entidades comunitárias. As organizações não-governamentais, as igrejas, os movimentos profissionais como os médicos sem fronteira atuam como uma válvula de escape nas deficiências do Estado e do mercado. É a entidade de direitos civis que vai defender os interesses do cidadão junto à Justiça e ao Congresso. É a solidariedade de uma organização religiosa que vai ajudar muitos desempregados excluídos pelo mercado".

Confiando no poder das organizações comunitárias, o cidadão vai encontrar nelas a solidariedade sem interesses, pois a família, os vizinhos e sua comunidade representam a reserva moral da sociedade. Embora Offe (id.) ressalte que, se conduzidas por um grupo de interesses comuns, podem ser injustas, corporativas e egoístas, esclarece que é inegável o resultado positivo da ação comunitária. Defende, inclusive, por isso mesmo, um triângulo entre as três forças, sem a hegemonia de nenhum setor.

Tornar inteligíveis esses processos de mudanças, segundo observam Velloso \& Martins ${ }^{4}$, requer sejamos perspicazes para distinguir quais os dados, efetivamente relevantes, e dispor de esquemas conceituais capazes de ordená-los de modo significante. Primeiramente, porque os dados são ainda imprecisos e não permitem distinguir com clareza o que são apenas tendências do que já são processos de mudanças e, segundo, porque implicam também a própria maneira de percebê-las.

As mudanças em curso dizem respeito à própria estrutura do poder mundial, que antes estava centrada numa bipolarização entre os países capitalistas e os países socialistas; à dissociação entre o econômico, o político e o militar, enquanto recursos de poder; à interdependência econômica entre os países capitalistas altamente industrializados, a partir do ressurgimento dos principais países europeus e do Japão; à emergência de outros países (sudeste asiático, produtores de petróleo etc.), ampliando a diversificação do mapa geoeconômico mundial, impedindo a ascensão natural americana como única potência mundial - embora sua supremacia econômica e militar seja incontestável, eles não podem prescindir de um conselho diretor, composto dos principais países capitalistas, atados entre si pela interdependência. A exemplo, o Grupo dos 7. Outro aspecto enfocado por Velloso \& Martins (op.cit.) diz respeito à regionalização e à globalização, que, embora pareçam paradoxais, constituem tendências insuspeitadas. A globalização resulta da ação de expansão do capital, em plano mundial, enquanto se realiza no âmbito dos países desenvolvidos. A regionalização representa uma tentativa de o Estadonação impor regras à globalização. Há também a questão do conjunto de mudanças em relação a avanços tecnológicos e novas formas de organização da produção e da comercialização.

Segundo M. Castells, cuja obra é analisada por Stalder ${ }^{5}$, a nossa sociedade se desenvolveu a partir da oposição bipolar do "Net" (o coletivo) e do "Self" (o indivíduo, o sujeito). O "Net" possibilita novas estruturas organizacionais baseadas no uso sutil da mídia de comunicação em rede; o "Self" simboliza atividades mediante as quais o indivíduo tenta reafirmar sua identidade sob condições de mudança estrutural e de instabilidade. Nesse sentido, o processo de autoconstrução da identidade é uma força dinâmica na formação da sociedade. $\mathrm{O}$ problema da identidade, no entanto, não é um conflito apenas do indivíduo. Segundo Castells, o Estado-nação também perde seu poder embora não sua influência -, e à perda do poder, segue-se a perda da soberania, efeito da globalização. $O$ resultado desse fenômeno é a crise das democracias liberais, pois as instituições democráticas tradicionais estão sendo destituídas de significado e legitimidade: elas perderam sua identidade. Assim como Offe ${ }^{6}$, Castells deposita muita esperança nos movimentos sociais para desenvolver novas formas de identidade e democracia.

Chama, também, a atenção, nesse painel de mudanças estruturais, o crescimento da indústria da informação como um componente estratégico (Gaiia ${ }^{7}$.

Nesse contexto, Vitro ${ }^{8}$ nos introduz o conceito de uma economia do desenvolvimento baseado em conhecimento, segundo o qual "o crescimento econômico não é conseqüência natural de mais e mais informação. Ele está mais relacionado ao grau de desenvolvimento dos mecanismos que numa sociedade estimulam a capacidade das pessoas de criar e aplicar conhecimentos". De acordo com o autor, a informação contribui de dois modos para o crescimento e o desenvolvimento: primeiro, porque a produção e distribuição de informação é uma atividade econômica; segundo, porque a aplicação do conhecimento melhora a produtividade e a qualidade de outros bens e serviços. O caráter dos mecanismos socioeconômicos que permitem aos membros de uma sociedade ampliar e elevar sua base de conhecimento, 
ainda segundo Vitro (id.), é característica importante e distintiva de identificação daquelas sociedades capazes de resolver suas várias e crescentes necessidades. $\mathrm{Na}$ perspectiva apresentada pelo autor, as pessoas, cada vez mais, no mundo inteiro, em resposta ao conjunto único de condições históricas, culturais, econômicas e políticas de cada sociedade estão engajadas na melhoria da qualidade de suas vidas, referente à autodeterminação, crescimento econômico, respeito ao meio ambiente, melhores condições de saúde. A partir de novas abordagens desses problemas globais, na busca de novos equilíbrios na distribuição de recursos, na renovação da organização social, estão moldando uma economia global baseada em um processo de desenvolvimento sustentável e que, desejamos, leve-nos em direção a uma sociedade mais justa e solidária.

\section{A SOCIEDADE DA INFORMAÇÃO}

Emergindo dessas transformações e a partir de novos paradigmas, sustentada por novas tecnologias de informação e comunicações, como a trajetória mais provável pela ampliação da globalização e prevalecendose de uma nova hegemonia, delineia-se a Sociedade da Informação, ou Sociedade do Conhecimento.

Segundo Toffler \& Toffler ${ }^{9}$, essa nova civilização, resultante do terceiro grande fluxo de mudança na história da humanidade - a Terceira Onda* -, impõe um novo código de comportamento:

"Essa nova civilização traz consigo novos estilos de família; maneiras diferentes de trabalhar, amar e viver; uma nova economia; novos conflitos políticos; e acima de tudo uma consciência modificada".

Masuda ${ }^{10}$ desenha-nos, nitidamente, o perfil dessa sociedade emergente. A base dessa sociedade será a produção de valores informacionais, intangíveis, em substituição aos valores tangíveis, em que prevalece a indústria do conhecimento, quaternária, expandindo-se a partir de uma economia sinérgica e da utilização compartilhada dos bens. A sociedade da informação será, para ele, uma comunidade voluntária, voltada para o benefício social.

\footnotetext{
*Não é objetivo desse artigo aprofundar-se na análise desse fenômeno. Utilizamos apenas para contextualizar o processo de mudança que molda a sociedade emergente.
}

Para Drucker ${ }^{11}$, assim como para Masuda, o recurso econômico básico dessa sociedade pós-industrial será o conhecimento. Ela não será uma sociedade nem nãocapitalista, nem anticapitalista, mas, antes, utilizará o mercado como instrumento de integração econômica. Seu desafio social será o de oferecer dignidade aos trabalhadores em serviços - a maioria da população mesmo nos países mais adiantados - que carecem de educação necessária para serem trabalhadores do conhecimento. Por sua vez, esses últimos serão considerados os principais grupos sociais da sociedade do conhecimento.

Drahos, segundo Ataíde ${ }^{12}$, ao contrário de Masuda, entende que a sociedade da informação corre o risco de se fechar em feudos, prevalecendo os interesses dos "barões da mídia", buscando grandes lucros e acentuando as desigualdades. Alerta para o risco de limitação dos direitos de informação do cidadão e julga que a globalização, a privatização dos meios de telecomunicações e os direitos de propriedade intelectual estão a serviço de grupos poderosos.

Adotando a mesma postura de Drahos, Martin \& Schuman ${ }^{13}$ alertam para o risco de a globalização levar o mundo para uma sociedade de exclusão e desemprego - a “sociedade 20 por 80 ". Ao mesmo tempo, enfatizam que o afastamento do modelo tradicional de desenvolvimento econômico não tem de, necessariamente, levar à desagregação social, mas pode perfeitamente buscar novas formas de bem-estar, desde que se desenvolvam ações para o fortalecimento da sociedade civil.

Em uma sociedade em que a economia é baseada em conhecimento, segundo nos explica Romer ${ }^{14}$, o crescimento não tem limite, porque produz riqueza refinando idéias - porque o conhecimento transmitido permanece na fonte: não há escassez de recursos. Nessa nova economia, segundo o autor, o padrão geral de vida da população deverá melhorar, em termos absolutos, embora, em termos relativos, o desnível entre ricos e pobres se acentue.

Entretanto, conforme nos alerta Miranda ${ }^{15}$, a simples existência da informação não garante conhecimento e desenvolvimento, importando saber se o seu uso potencial vale mais que seu uso real. Nesse sentido, os imensos arquivos de dados deixam de ser apenas repositórios de informação e valorizam-se como importantes fontes de conhecimento. 


\section{CONSTRUINDO A CIDADANIA: O FATOR EDUCAÇÃO}

A conscientização é um processo que permite ao homem compreender a realidade que o cerca, como ela se estrutura, o que ele é e a reagir a essa realidade, assumindo seu destino e dos seus semelhantes com autonomia, buscando sempre melhores condições de vida. É um "ser aberto, insatisfeito, não completo" $\left(\right.$ Araújo ${ }^{16}$ ).

Nesse processo de conscientização e busca, vai descobrindo a dimensão de suas possibilidades e necessidades, bem como as formas de superá-las, mediante sua participação na sociedade na qual está inserido. Assim, podemos identificar dois aspectos de sua personalidade: sociabilidade - enquanto "a propensão do homem para viver junto com os outros e comunicar-se com eles, tornálos participantes das próprias experiências e dos próprios desejos, conviver com eles as mesmas emoções e os mesmos bens", e politicidade - entendendo-se como "o conjunto de relações que o indivíduo mantém com os outros, enquanto faz parte de um grupo social". (Battista Mondin, apud. Betioli $\left.{ }^{17}\right)$. Na realidade, são dois aspectos de um mesmo fenômeno: por ser sociável, o homem procura conviver com seus semelhantes e formar com eles certas associações estáveis. Uma vez inserido em grupos organizados, ele torna-se um "ser político", ou seja, membro de uma polis, garantindo direitos e assumindo deveres (Betioli, id.)

A cidadania, então, é um status concedido àqueles que são elementos integrais de uma comunidade (Targino ${ }^{18}$ ). Nesse sentido, a idéia de cidadania implica um conceito de igualdade, uma vez que todos os que possuem esse status são iguais, no que diz respeito aos direitos e obrigações pertinentes ao status (Targino, id.). Mas, contrariamente à idéia de igualdade que a cidadania sugere, a estratificação social, que concede o status, é um sistema de desigualdade que se acentua e se agrava no sistema capitalista. Como entender isso?

Etimologicamente, cidadão significa membro livre de uma determinada cidade, por origem ou adoção, assumindo um conjunto de raízes culturais, políticas e sociais, movimentando-se nesse conglomerado sociopolítico e econômico, dinamizando o complexo cultural, sugerindo uma idéia coletiva e pluralista dos termos cidadania e cidadão. Assim, o cidadão-indivíduo move-se no social e o cidadão-coletivo participa do social (Varela $\left.{ }^{19}\right)$.
A definição de cidadão de Aurélio Buarque (apud. Targino ${ }^{20}$ ) refere-se ao indivíduo no gozo dos direitos civis e políticos de um Estado, ou no desempenho de seus deveres para com este. Os direitos sociais estão excluídos, portanto, explicitamente, dessa definição. $\mathrm{O}$ desenvolvimento da cidadania, assim, exerce pouca influência sobre a desigualdade. Segundo essa visão, os direitos sociais desenvolvem-se à margem da proteção do Estado. Para melhor compreendermos essa desagregação dos direitos fundamentais do homem, lancemos um olhar sobre Marshall (citado por Araújo, 1998, p. 7; e Varela, 1999) ${ }^{21}$, que apontou três elementos constitutivos dos direitos de cidadania, em sua evolução histórica e pertinente à era moderna:

- os direitos civis representam os direitos do indivíduo na sociedade e referem-se à liberdade individual;

- os direitos políticos são conquistados a partir dos direitos civis assegurados e ampliados pelo direito de participar do exercício do poder, mediante o voto ou investido de autoridade, como representante eleito;

- os direitos sociais - direito a usufruir bem-estar social e econômico, de acordo com padrões que garantam a dignidade humana.

Segundo nos aponta Targino $(1991)^{22}$, esses elementos se fundem ou se confundem, distanciam-se ou desaparecem, de acordo com as circunstâncias históricas de cada povo. Não cabe discutir aqui a evolução histórica ou os fatores implicados nesse processo. O que importa saber é que um mínimo desses direitos seja reconhecido e assegurado pelas autoridades instituídas e competentes. Conforme nos reporta Araújo (1998) ${ }^{23}$, as instituições mais intimamente ligadas aos direitos sociais são o sistema educacional e os serviços sociais. Assim também entende Targino (1991) ${ }^{24}$, quando, ao referir-se ao caso específico da educação como elemento basilar dos direitos sociais, afirma que o direito à educação afeta o status da cidadania, se entendermos o direito à educação como o direito do cidadão adulto ter sido educado e informado.

Em um quadro de economia globalizada e da sociedade organizada a partir do paradigma do conhecimento, como vimos, o fator educação assume papel fundamental nesse processo. É ela que viabiliza o projeto da sociedade do conhecimento e operacionaliza a formação e o exercício da cidadania. Como salienta Oriá $(1997)^{25}$, ao socializar o conhecimento historicamente produzido e preparar as atuais e futuras gerações para a construção de novos conhecimentos, a escola está cumprindo seu papel social. 
Por essa perspectiva, e sob a ótica de Marinho (1993) ${ }^{26}$, a leitura assume função essencial para a formação da cidadania, por sua característica dinâmica, tanto no processo de ensino-aprendizagem - como instrumento de permanente formação intelectual do indivíduo -, quanto como prática social - consubstanciada na interrelação leitor e autor, mediada pelo texto, o que implica diferentes repertórios culturais, códigos lingüísticos, interpretações e reflexões sobre a realidade, propiciando alienação ou conscientização. Alienação, quando a leitura é vista como processo mecânico, autômato, o leitor é sujeito passivo e o texto não propicia reflexão - é possuidor de "uma única verdade": a leitura resulta, então, no dizer de Paulo Freire, na "cultura do silêncio". Conscientização, quando o ato de ler, a partir da constatação e da reflexão, proporciona ao leitor a transformação de si mesmo e da sua realidade, embora saibamos que qualquer texto é direcionado e está imbuído de ideologias. Não existe neutralidade. Mas, quando essa ideologia assume o papel de orientador da ação, renunciando à manipulação consciente para dominação discursiva ou à criação de uma "falsa consciência", permite que o processo leitura alargue a "capacidade de simbolização dos códigos, fornecendo uma identidade social e política ao indivíduo" (Marinho, id.).

\section{CONCLUSÃO}

Por mais que possamos antecipar o futuro e moldar seus contornos, ele ainda não está pronto. Perceber que as transformações em curso são estruturais e decorrentes do caráter orgânico e mutável da própria sociedade, marcada por contradições e desigualdades, e que essa evolução é resultante do desenvolvimento científico e tecnológico, bem como das forças produtivas que a compõem, significa abrir espaço para políticas que apresentem soluções possíveis às equações sociais presentes e futuras. Certamente, é possível pensar em ações que se beneficiem da globalização, promovam o desenvolvimento e reduzam os conflitos.

Uma delas é oferecer um modelo educacional que priorize a questão da cidadania, ofereça maior eficiência no uso dos recursos públicos, com base na diversidade e interdisciplinaridade, multicultural (Oriáa ${ }^{27}$ ), estabelecendo parâmetros curriculares preocupados com a cultural regional e local, que discuta questões como sexualidade, meio ambiente, ética e dignidade, direitos humanos e repúdio às discriminações, permitindo aos jovens acesso à tecnologia e preparando-os para o mercado de trabalho e para a cidadania (Souza, 1997) ${ }^{28}$.
Algumas experiências bem-sucedidas apontam para essa possibilidade: o Projeto Ilê-Ayê, em Salvador (em relação à questão da identidade afro-brasileira); o Grupo Mari (Grupo de Educação Indígena da Universidade de São Paulo); o Projeto Escola Candanga, no Distrito Federal (baseada no princípio do desenvolvimento humano pleno, integrando o cognitivo, o social e o cultural, envolvendo projetos como eleição direta nas escolas públicas; uma rede pública de comunicações para divulgar projetos educacionais; benefício às famílias carentes para manter seus filhos na escola, tirando-os da rua e do trabalho; abertura das escolas públicas, aos sábados, para confraternizar pais, alunos e educadores e discutir problemas contemporâneos, com ajuda de recursos audiovisuais; capacitação e aprimoramento de profissionais do ensino e educação de adultos* (Oriá, 1997, op. cit. ; Ibañez, 1997²9). Em nível internacional, podemos citar a cidade francesa de Parthenay, que usa as tecnologias de informação para ajudar a democracia* ${ }^{* *}\left(\right.$ Leiria, 1999) ${ }^{30}$.

Garantir cidadania, assegurar os direitos de acesso à informação e à educação para os indivíduos, agora e no futuro, implica reduzir os riscos alegados pelos autores analisados, oferecendo aos trabalhadores em serviços, se não o conhecimento, pelo menos as técnicas instrumentos que proporcionar-lhes-ão dignidade e sobrevivência, em uma sociedade altamente competitiva.

\section{REFERÊNCIAS BIBLIOGRÁFICAS}

1. FERREIRA, S.M.S.P. Novos paradigmas e novos usuários de informação. Ci. Inf. v. 25, n.2, 1995. Versão eletrônica.

2. TARGINO, M. das G.. Biblioteconomia, informação e cidadania. $R$. Esc. Bibliotecon. UFMG, Belo Horizonte, v. 20, n. 2, p. 149 a 160 jul./dez. 1991.

3. OFFE, C. O novo poder. Veja, vol. 31, n. 14, p. 11 a 13, abr. 1998. Entrevista concedida a Thomas Traumann.

4. VELLOSO, J.P.R., \& MARTINS, L. (orgs.). A nova ordem mundial em questão. Rio de Janeiro : J. Olympio, 1993. 433p.

5. STALDER, F. The network paradigm : social formations in the age of information. The Information Society, v. 14, p. 301-308, 1998.

6. Op. cit.

7. GAIIA - Global Alliance of Information Industry Associations : Declaração de Diplomacia Comercial sobre o Desenvolvimento Sustentável e a Indústria da Informação (Declaração de Tóquio), 29 de maio de 1992. R. Bibliotecon. UFMG, Belo Horizonte, v. 22, n.1, p. 89-105, jan./jun. 1993.

\footnotetext{
* Os projetos Gestão Democrática, Canal Educativo, Bolsa-Escola, Escola da Família, Escola de Aperfeiçoamento, do governo de Cristóvam Buarque, entre 1994 a 1998.
}

** O site da cidade na Internet é http://www.district-partheney.fr 


\section{A questão cidadania na sociedade da informação}

8. VITRO, R.A. Para uma economia do desenvolvimento baseada em conhecimento. R. Bibliotecon. UFMG, Belo Horizonte, v. 22, n. 1, p. 9 a 37, jan./jun. 1993.

9. TOFFlER, A., \& TOFFLER, H. Criando uma nova civilização : a política da terceira onda. Rio de Janeiro : Record, 1995. 142 p.

10. MASUDA, Y. A sociedade da informação como sociedade pós-industrial. Rio de Janeiro : Ed. Rio, 1982. 210 p.

11. DRUCKER, P. Sociedade pós-capitalista. 6.ed. São Paulo : Pioneira, 1997. 187 p.

12. ATAÍDE, M.E.M. O lado perverso da globalização na sociedade da informação. Ci. Inf. On-line.

13. MARTIN, H-P., \& SCHUMANN, H. A armadilha da globalização : o assalto à democracia e ao bem-estar social. 2.ed. São Paulo : Globo, 1998. 352 p.

14. ROMER, P. (1999). Sai o átomo, entra o bit. Veja, v. 32, n. 27, 7 jul. 1999. Economia e Negócios. Entrevista.

15. MIRANDA, A. Globalización y sistemas de información: nuevos paradigmas y nuevos desafíos. Em: CONFERENCIA REGIONAL POLÍTICAS Y ESTRATEGIAS PARA LA TRANSFORMACIONA DE LA EDUCACIÓN SUPERIOR EN AMERCIA LATINA Y EL CARIBE (1996 : La Habana). Documentos.

16. ARAÚJO, E.A. de. A construção social da informação : práticas informacionais no contexto de organizações não-governamentais - ONGs brasileiras. Brasília : UnB, 1998. 221 f. (Tese - Doutorado - Ciência da Informação - UnB/CID).
17. BETIOLI, A.B. (1995). Introdução ao direito : lições de propedêutica jurídica. 3.ed. São Paulo : Letras \& Letras, 1995. 439 p. 439 p.

18. Op. cit.

19. VARELA, A.V. Informação e construção da cidadania. Brasília, 1999. 105 f. (Dissertação - Mestrado - Ciência da Informação - UnB/ CID).

20. Obra citada.

21. Obras citadas.

22. Idem.

23. Idem.

24. Ibidem.

25. ORIÁ, R. Educação, cidadania, diversidade cultural. Humanidades, Brasília, v. 43, p. 151 a159, 1997.

26. MARINHO, R.R. (1993). Leitura : um caminho para a cidadania. Trans-in-formação, Campinas, v. 5, n. 1/2/3, p. 90 a 94, jan./dez., 1993.

27. Op. cit.

28. SOUZA, P.R. Globalização e educação: rumos e perspectivas. Humanidades, Brasília, n, 43, p. 6 a 11, 1997.

29. IBAÑEZ, A. Escola cidadã e de qualidade. Humanidades, Brasília, n. 43, p. 12 a $18,1997$.

30. LEIRIA, 1. Mergulho no futuro : os perigos da sociedade da informação. Internet.br, Rio de Janeiro, v. 3, n. 36, p. 20, maio 1999. 